\title{
A REVIEW ON INDOOR SMART ENERGY MANAGEMET SYSTEM
}

\author{
${ }^{1} \mathrm{Li}$ Woon Koay and ${ }^{2}$ Yasir Hashim \\ ${ }^{1,2}$ Faculty of Engineering Technology, University Malaysia Pahang, 26300, Kuantan, Pahang, Malaysia \\ 2yasirhashim@ump.edu.my
}

\begin{abstract}
One of the best choices to reserve energy is converted the original home into an intelligent one or known as "Smart Home". In this paper, a review on samart energy management system was presented. Various novel methods and technologies are being extensively explored.
\end{abstract}

Index Terms-Smart, Energy, Management, System,

\section{INTRODUCTION}

Recently, the news relates to natural disaster or ecosystem imbalance is spread widely every moment, everywhere. The planet's natural ecosystem had been destroyed and this make severe impact to us like emission of $\mathrm{CO} 2$ and causing disaster occur like global warming and haze. Not only that according to the International Energy Agency (IEA)[1] , the total world energy consumption was 157,481 terawatthour(TWh) in 2013, 155,505 TWh in 2012, 143,851 TWh in 2008, 133,602 TWh in 2005, 117,687 TWh in 2000, and 102,569 TWh in 1990. This shows that the demand of energy consumption is increasing year by year. Information currently has discussed that most citizens already have a preconceived idea to make homes become more intelligent. This topic is starting to gain awareness in public which around us. Save the planet to be a better place in future start from our action now which is apply additional methods in people daily housework to decrease the need of energy consumption. One of the best choices to reserve energy is converted their original home into an intelligent one or known as "Smart Home".

Smart Home defines the building automation in a private home, in which single components (sensors and actuators) are networked together in order to form an intelligent system. The process will be a main command center processes the information which record by the sensors and the command will be transmitted appropriately to fitting actuators. After that, the connection is combined with intelligent control to run the system completely. This will help to reduce energy consumption, ensures more safety and also make more comfort in that environment. There are a lot of researchers have studied about the smart system using different concepts and methods to achieve the same objectives. At the same time, the research makes improvement and produce more advance for te current system to become better compare to existing systems.

\section{ENERGY SAVING}

The authors challenge the widely held view that using green roof as current building regulations to affect annual building energy consumption[2]. In other words, [2] emphasizes that the potential of green roofs offer in relation of saving energy and also greatly reduces the proportion of solar radiation. Many studies have been conducted that the green roofs assess the extent of energy savings with reduce annual heating and cooling loads due to the poor insulation value of green roofs, and also assessing their potential in other factor such in the context of building use and environmental education to the community. Table 1 has showed that energy saving potential based on different levels of insulated buildings. 
Table 1 Energy saving potential of green roof on low, moderately and heavily insulated buildings in Athens, Greece [3].

\begin{tabular}{llllll}
\hline Roof construction & $\begin{array}{l}\text { U-Value } \\
\text { without green } \\
\text { roof }\left(\mathrm{W} / \mathrm{m}^{2} \mathrm{~K}\right)\end{array}$ & $\begin{array}{l}\text { U-Value with } \\
\text { green roof } \\
\left(\mathrm{W} / \mathrm{m}^{2} \mathrm{~K}\right)\end{array}$ & $\begin{array}{l}\text { Annual energy } \\
\text { saving\% for } \\
\text { heating }\end{array}$ & $\begin{array}{l}\text { Annual energy } \\
\text { saving\% for } \\
\text { cooling }\end{array}$ & $\begin{array}{l}\text { Total annual } \\
\text { energy saving }\end{array}$ \\
\hline Well insulated & $0.26-0.4$ & $0.24-0.34$ & $8-9 \%$ & 0 & $2 \%$ \\
Moderately insulated & $0.74-0.80$ & $0.55-0.59$ & $13 \%$ & $0-4 \%$ & $3-7 \%$ \\
Non insulated & $7.76-18.18$ & $1.73-1.99$ & $45-46 \%$ & $22-45 \%$ & $31-44 \%$ \\
\hline
\end{tabular}

A broader perspective has been adopted by [4] who argued that activity of recycling building materials able to contribute additional energy savings as priority to builds the life cycle energy assessment (LCEA) and also the operation of other life cycle phases. In [4], it utilizes the existing building energy codes with appliances standards, and labeling and information of programs can help reduce energy consumption. In [4] has shown that using set-point temperature close to $26^{\circ} \mathrm{C}$, practicing load shedding, using appropriate sized windows, employing glazing with lower heat transfer coefficients, all of this simple energy efficiency and no-cost energy conservation behavior may prove effective in reducing the energy consumption during operation. Not only that, the energy efficiency able to contribute in reducing a building operating energy profile, and reduce using natural resources due to recycling the building materials. Table 2 has showed that the analysis of energy saving strategies by different phase. This will improve in terms of energy performance of buildings and also conserve energy and natural resources by utilize the use of recovery and recycling of building materials.

Table 2 Analysis of energy saving strategies by phase [4].

\begin{tabular}{llc}
\hline Strategy & Phase affected & $\begin{array}{c}\text { \% Energy saved } \\
\text { (in phase) }\end{array}$ \\
\hline Chiller replacement & Operating & $17 \%$ \\
Periodic load shedding & Operating & $12.50 \%$ \\
Set-point temperature adjustment & Operating & $7 \%$ \\
WWR reduction (0.5-0.45) & Operating & $2 \%$ \\
WWR reduction (0.5-0.35) & Operating & $6.20 \%$ \\
High performance glazing & Operating & $3.70 \%$ \\
Recycling of building materials & Manufacturing & $8.90 \%$ \\
\hline
\end{tabular}

\section{III.INDOOR ENERGY MANAGEMENT SYSTEM}

A number of researchers have reported an indoor energy management system which is using indoor setpoint standard of air-conditioned spaces as a tool to control electrical energy consumption in Thailand [5]. It will control the indoor set-point temperature at a certain range of values to assess the assumption of electrical energy and environmental saving potentials in Thailand. In [5], it shows the concept is proposed due to some factors which are highly consume electricity energy by different sectors such industrial, commercial, residential and others, greenhouse emission causing warm the atmosphere, and $\mathrm{CO}_{2}$ emissions to the environment caused by office building depend on direct and indirect factors. Table 3 has shown that this energy saving is likely to reduce the electricity generation from power plants and able estimate the reduction of $\mathrm{CO}_{2}$ emissions from fuel used by the power sector after the room air temperature is set at $26^{\circ} \mathrm{C}$. This regulation measure has a big effect on reducing energy consumption and less GHG emissions.

Table 3 Total energy saving and $\mathrm{CO} 2$ reduction estimation based on room air temperature as 26 ${ }^{\circ} \mathbf{C}[5]$ 


\begin{tabular}{|c|c|c|c|c|c|c|c|}
\hline Room air temperature set at buildings $\left( \pm 0.5^{\circ} \mathrm{C}\right)$ & 20 & 21 & 22 & 23 & 24 & 25 & Total \\
\hline$\%$ of buildings set at above temperature & 2.57 & 3.88 & 6.25 & 13.16 & 28.49 & 23.29 & \\
\hline Electricity consumption by air-conditioning (GWh) & 187.55 & 283.14 & 456.10 & 960.36 & 2079.07 & 1699.60 & \\
\hline Increase in room set-point of temperature $\left({ }^{\circ} \mathrm{C}\right)$ & 6 & 5 & 4 & 3 & 2 & 1 & \\
\hline$\%$ Electricity saving & 36.84 & 30.70 & 24.56 & 18.42 & 12.28 & 6.14 & \\
\hline Total annual electricity saving (GWh/year) & 69.09 & 86.92 & 112.02 & 176.90 & 255.31 & 104.36 & 804.60 \\
\hline Total $\mathrm{CO}_{2}$ emission reduction (ktons/year) & 49.74 & 62.58 & 80.65 & 127.37 & 183.82 & 75.14 & 579.31 \\
\hline
\end{tabular}

Previous studies of energy saving have not dealt with smart home system, in [6] shows the concept of reduce energy consuming and simulate energy efficient behavioral mode is manipulated by keeping the thermal indoor environment close to neutral. The aim of [6] is to keep the Present Market Value (PMV) within predefined limits. A simulation is applied with different control actions such control the heating system, lighting system, windows, table fan, blinds that reduce the solar heat gain and direct energy transmission relate with clothing insulation values, metabolic rate and infiltration rate. In table 2 showed that building higher energy consumption is based on occupant behavior and it will affect building lower energy consumption with control criteria. It is very important of appropriate occupant behavior to reduce energy consumption to acclimatize buildings.

Table 4 Energy consumption in the simulations. The primary energy was calculated by multiplying electricity consumption by 2.5 according to the Danish building code. [7]

\begin{tabular}{|l|c|c|c|c|c|c|c|}
\hline $\begin{array}{l}\text { energy consumption pr. Year } \\
\text { [kWh/year] }\end{array}$ & $1 \mathrm{~A}$ & $1 \mathrm{~B}$ & $1 \mathrm{C}$ & $2 \mathrm{~A}$ & $2 \mathrm{~B}$ & $2 \mathrm{C}$ & No control \\
\hline Heating & 2532 & 2372 & 2346 & 923 & 768 & 720 & 1812 \\
Fan & 380.1 & 423.6 & 431.0 & 1.4 & 0.3 & 0.1 & 0.0 \\
Circulation Pump & 13 & 13 & 13 & 3 & 2 & 2 & 13 \\
Lighting & 174 & 172 & 171 & 187 & 189 & 189 & 131 \\
$\begin{array}{l}\text { Primary energy for heating, } \\
\text { ventilation and lighting }\end{array}$ & 3948 & 3891 & 3882 & 1400 & 1246 & 1198 & 2171 \\
\hline
\end{tabular}

\section{IV.SMART SYSTEMS}

According to [8] in Korea, a study of smart power control algorithm using RF communication in Smart Home Environment is made. In [8], it includes the use of current booster, an AC/DC converter, and a DC/DC converter to operate lights and to implements the concept with using standby power and RF communication as smart power control system among smart home technologies. Figure 1 has showed the scenario of the smart power control system. It shows perception in solving the security problem due to unsecured protocol and vulnerable security areas will be attacked by hackers. Therefore, wireless network environment is brought out to minimize the possibility of data losses in sensor network. It serves the system wireless networking technologies using radio frequency (RF) as a medium to transmit and receive data. It also suggests a method to solve inefficient energy management problem. According to [8], it uses standby power to make operation with the help of multiple-trans connection in series and it extracts a current from each trans. As a result, the extract current helps to control the light switch through RF communication. Before it receives the power directly, the system will convert an alternating current into a direct current. Figure 2 and 3 have shown that the design of inner and outer of the system. Besides of implementation of using RF communication to control light switch, it also implements monitoring system and Smartphone application to make user easier to use. Figure 4 and 5 have shown that a window of main program and screens of the smart power control application respectively. In conclusion, it proposed that this services not only apply in home network but also a factory, a commercial building and others to save energy by control the electric light system. In [8], it is needed to test safety when apply in gas valves, door locks and others in future work to perform a quality life. 


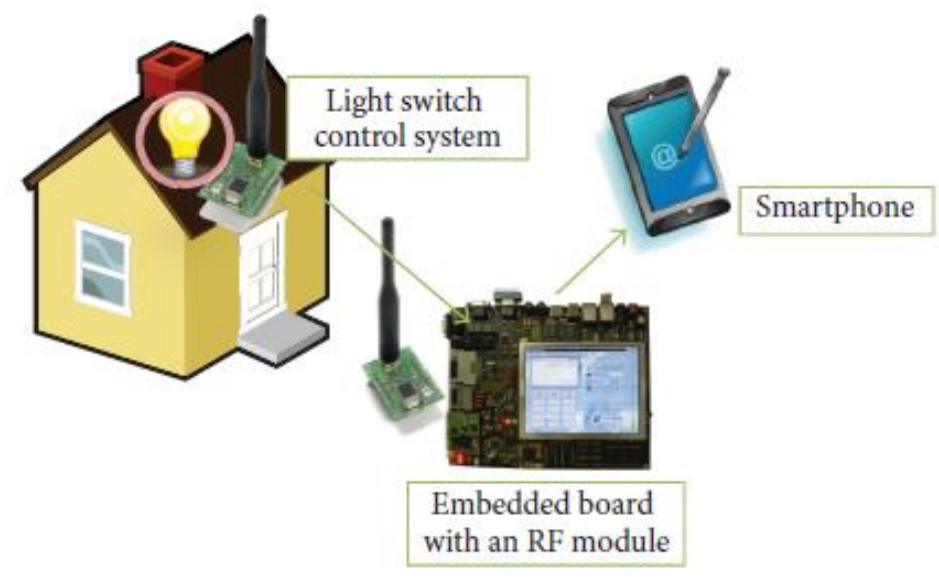

Figure 1 A scenario of the smart power control system proposed in [8]

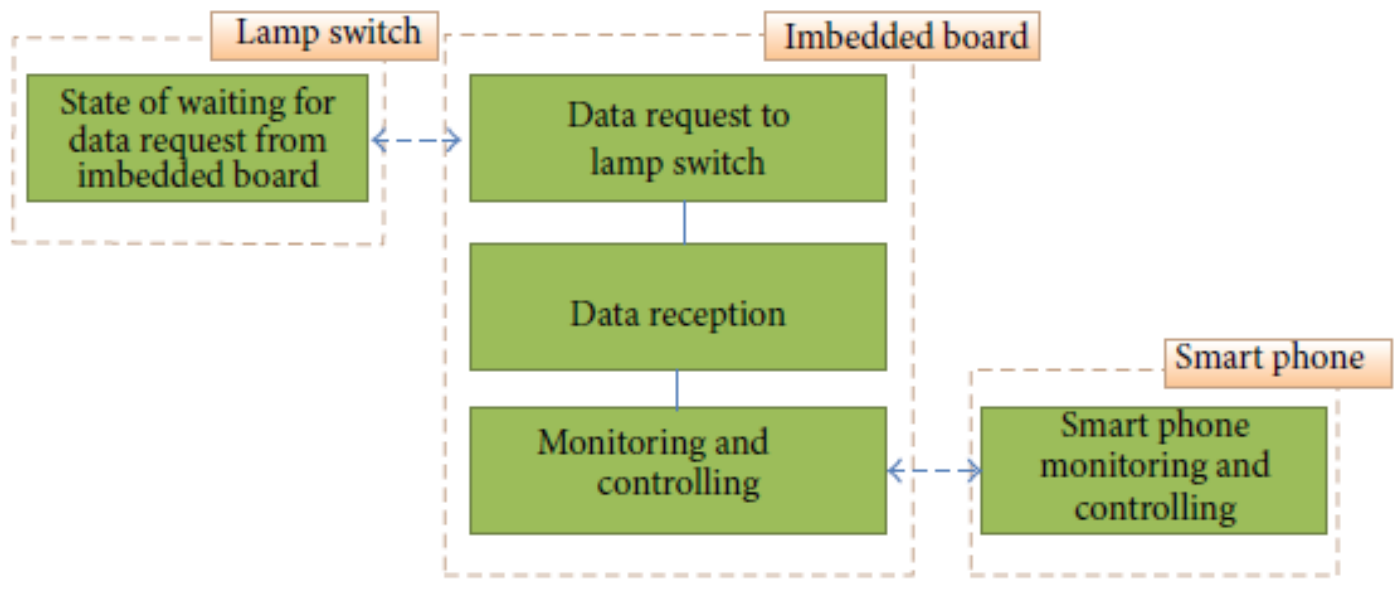

Figure 2 Inner action of the main program. 


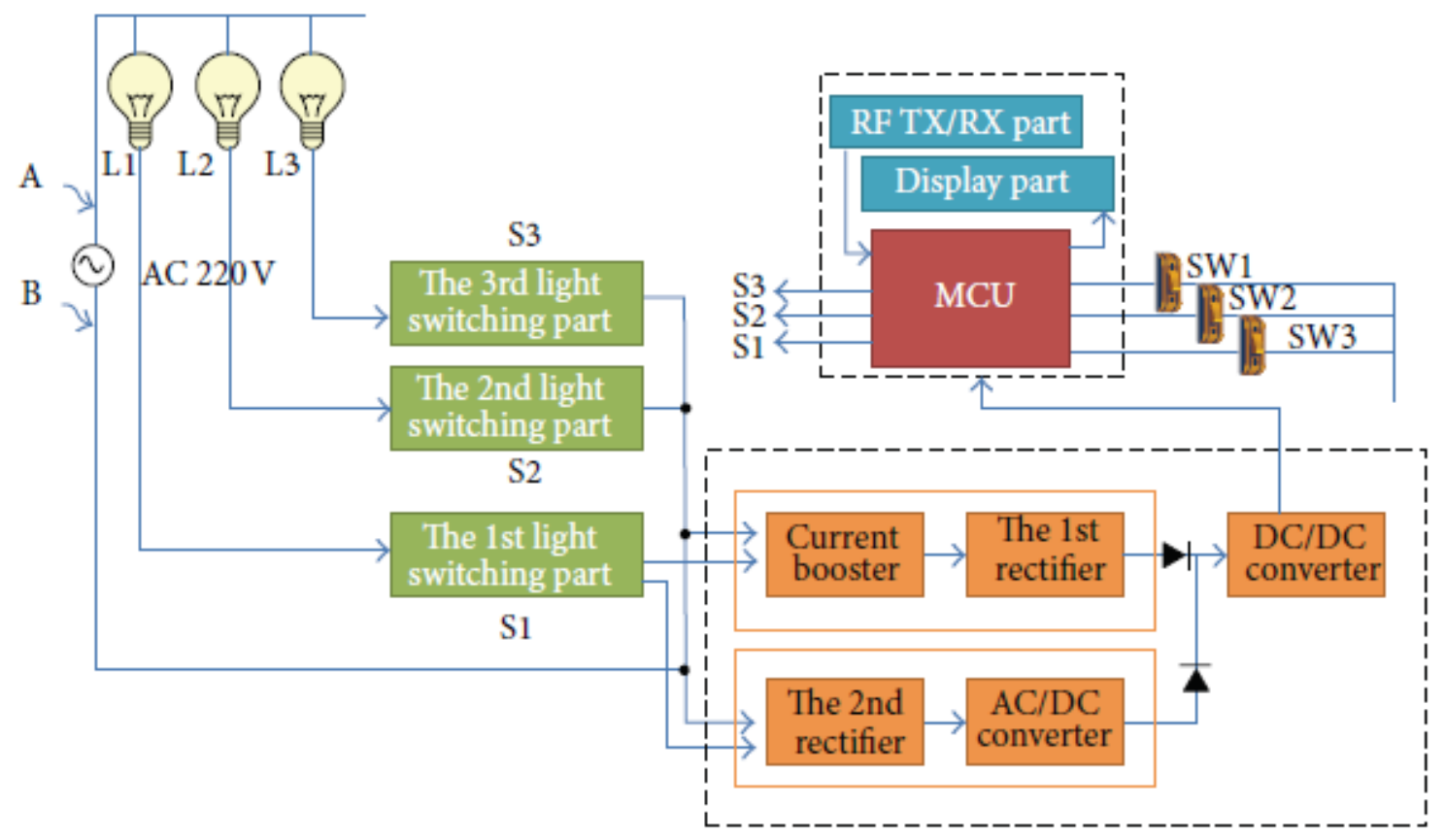

Figure 3 A diagram of the RF light switch system[9].

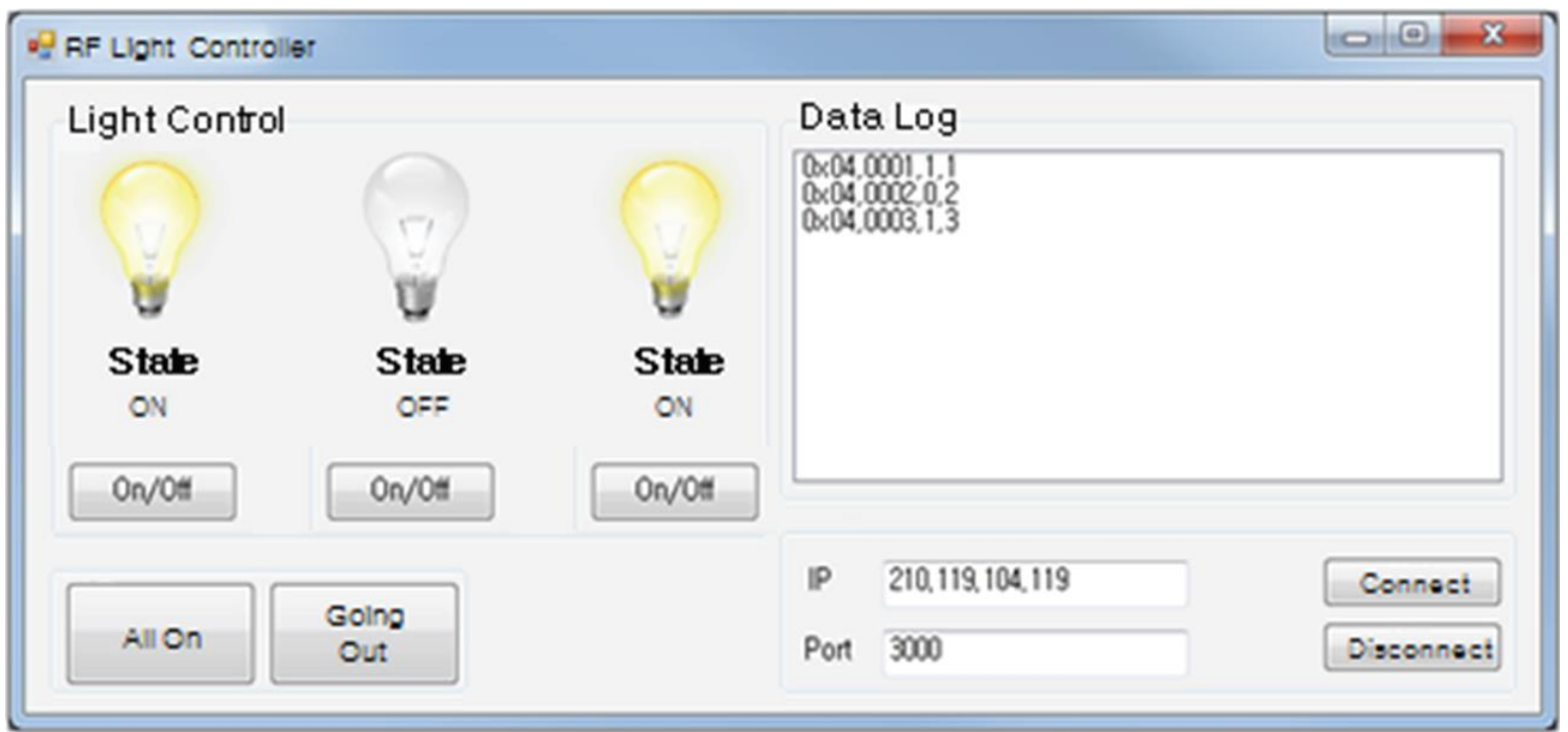

Figure $4 \mathrm{~A}$ window of the main program. 


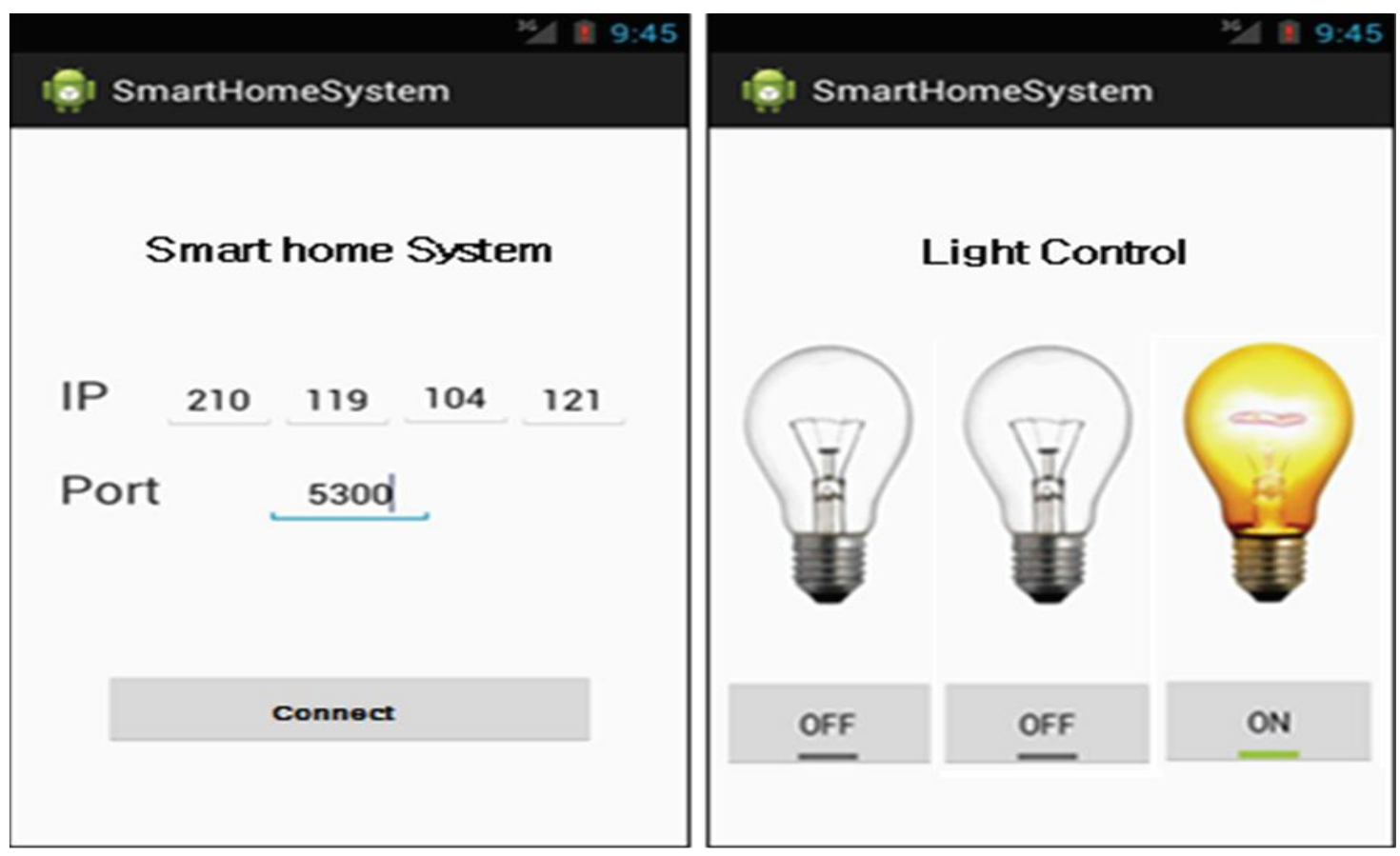

Figure 5 Screens of the smart power control application.

An integrated and low cost home automation system with flexible task scheduling concept based on idea of researchers in [10]. It contributes a Home Automation System using Robotics Integrated Development Environment (RIDE) in design, implementation and maintenance. In [10], integration is important for different kind of devices used in open system. Internet Of Things (IOT) devices in the system could be connected directly and also able provide a gateway from other network to internet which adapted to the Modbus interface. Figure 6 has showed the overview of home automation system. Besides that, RoboGraph in Petri Nets tool is proposed to use to complete a flexible task like programming and debugging [11]. Figure 7 has showed that Petri Net debug a main window. Secondly, it can be used to check the behavior and properties of modeled system and monitoring in the system. It also capable to analyze the data logged during execution. A prototype model has made with several sensors and actuators and also Modbus module interface with the Arduino. Figure 8 has showed that a Modbus module test the transaction in between building devices and central control system. In this combination of the system, it allows the user to monitor the house devices to achieve the main target and also create new behaviours to increment the number of devices in the system in future work. 


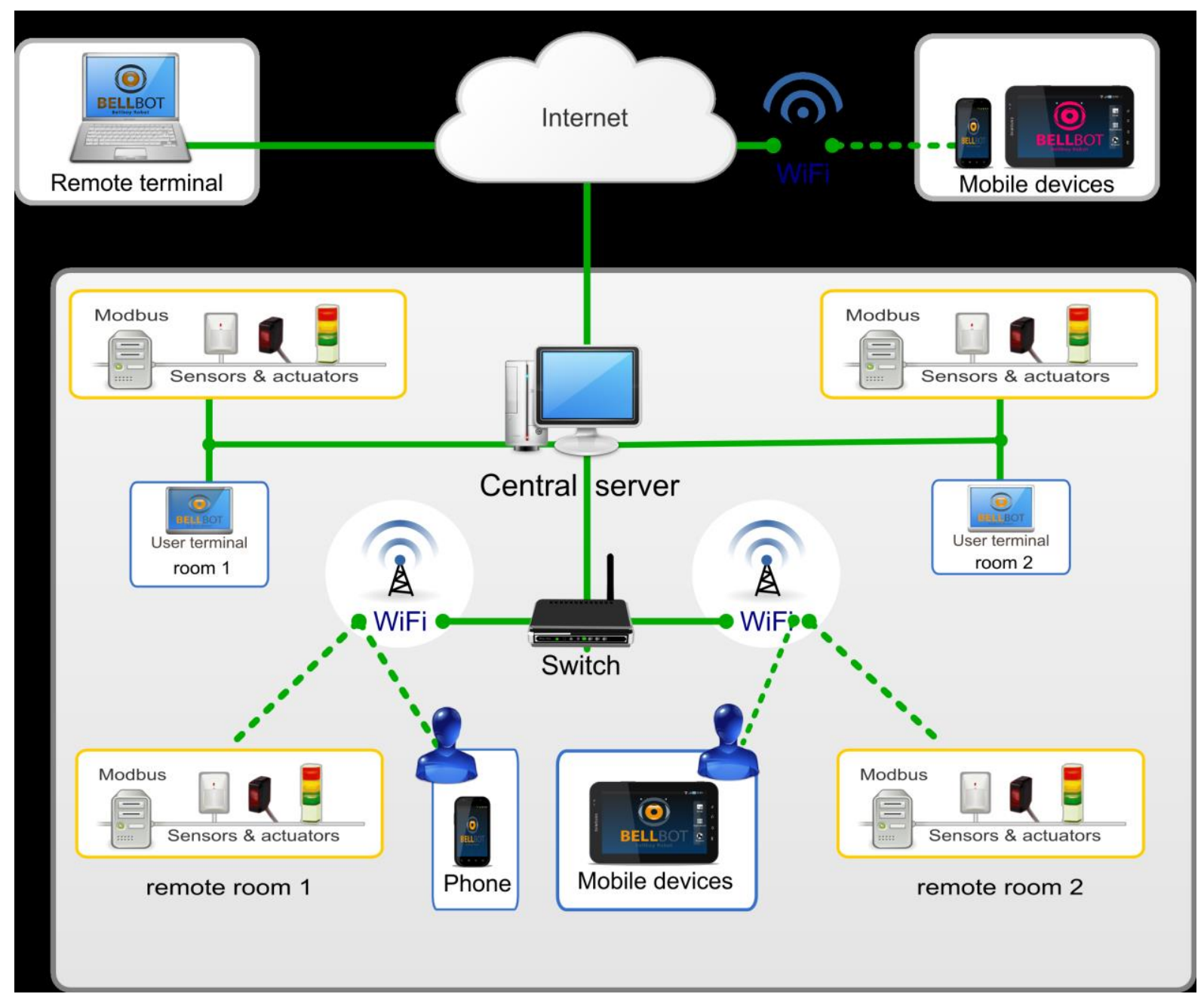

Figure 6 Overview of the home automation system.[10] 
INTERNATIONAL JOURNAL OF ENGINEERING TECHNOLOGY AND SCIENCES (IJETS) Vol.7 (1) June 2017 DOI: http://dx.doi.org/10.15282/ijets.7.2017.1.14.1076

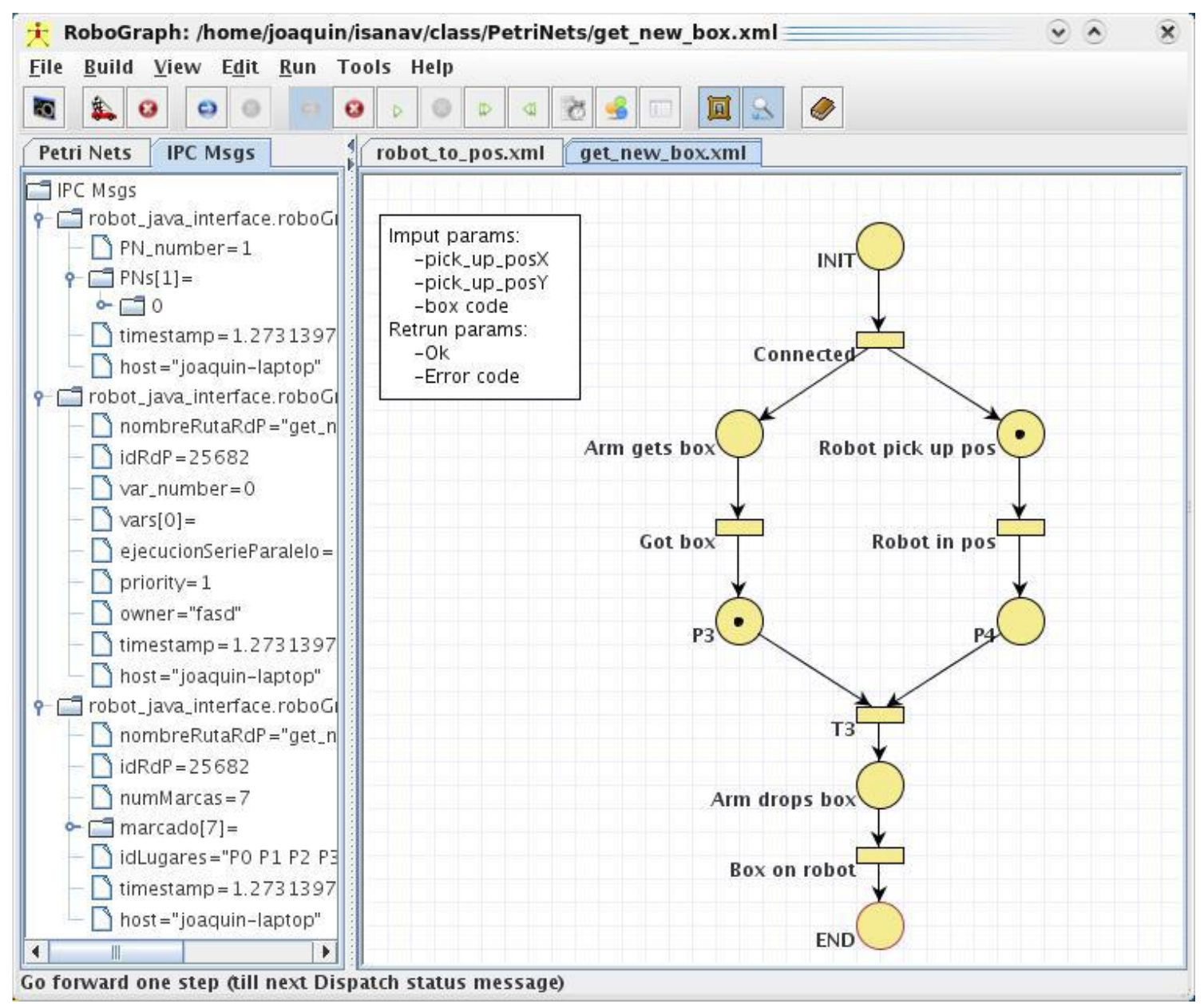

Figure 7 Petri net debugger main window.[11]

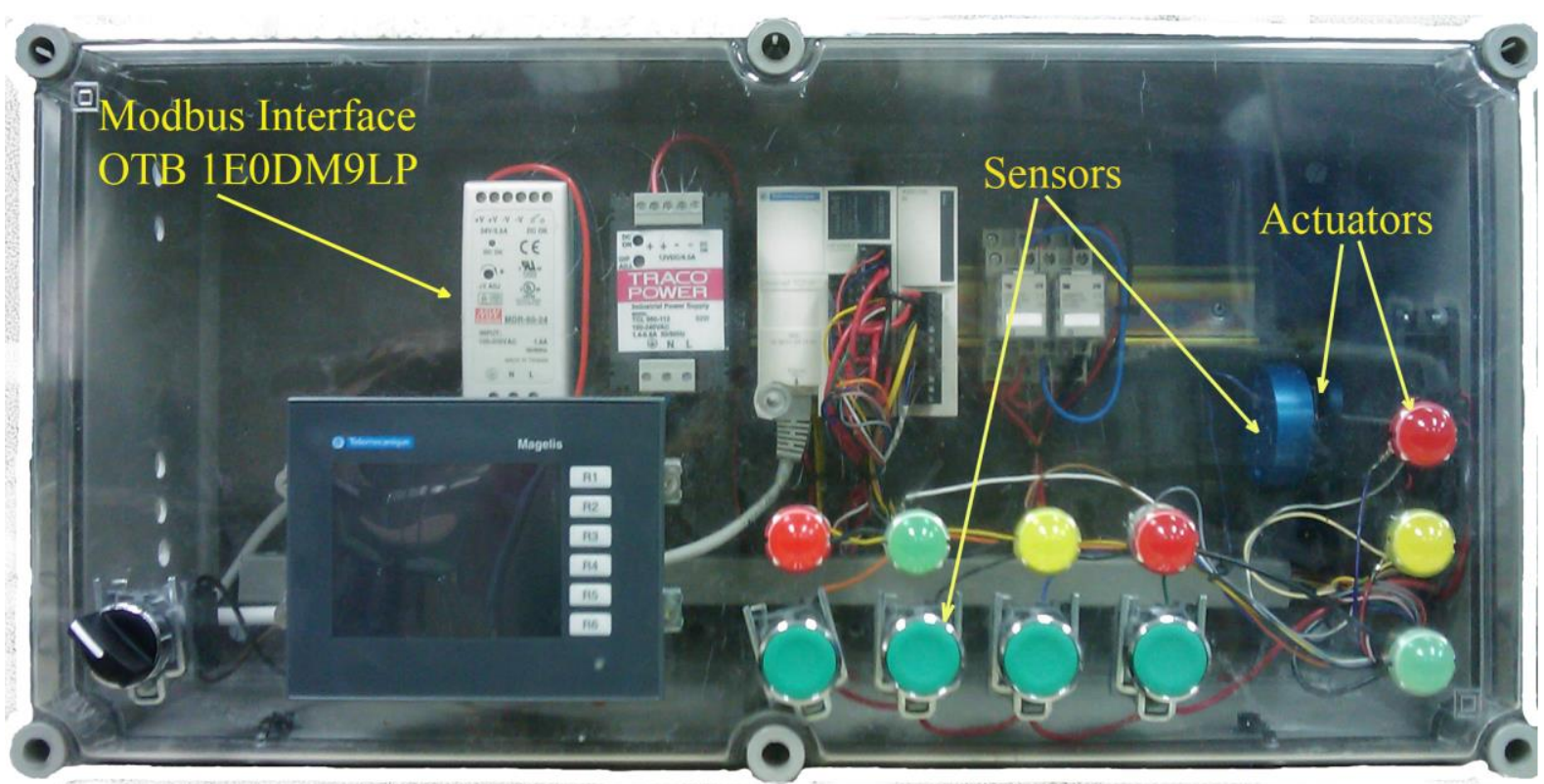

Figure 8 Modbus module used to test the transactions between building devices and the central control system. [11] 
From another view on Smart Home Technology, [12] proposed that the main objective is to clarify the main applications of various home automation technologies example for the use of elderly and the disabled persons able to self-care anytime. Another feature of Smart Home is to provide future enhancements needed but not only minimize energy conservation in household. In [12], world smart living concept is used instead of smart home to hit the main goal which is to provide an overall idea in the advancement of technological in the construction fields, and also proposed an area need more attention from the scholars and technicians. In view of all that has been mentioned so far, in the medical sector the primary goals of this study is to facilitate standard living, minimize energy conservation, and make self-sufficient for elderly or disabled persons with the concept of smart living. There are disadvantages of smart living appear due to some problems occur in implement electronic health records (EHR). Another obstacle which is it may become a great burden to affect people lifestyle, financial status, emotional and psychological wellbeing of family members if E-health is applied. It will become a worry for the user due to raises unnecessary issues. From [12] that has been discussed, it is conclude that the Smart Living or Smart Home technology can apply as identify, analyze and implement a wide range of aspects in both technological and non-technological areas, to live a life up expectations and realize a large-scale commercialization.

In [13] indicates that cooperative environment between the Interactive Digital TV (IDTV) and the networked home with the aim to achieve smart home. In [13], it has selected Multimedia Home Platform (MHP) standard and Open Service Gateway Initiative (OSGi) as platform and using XbundLET as a bridge to set up Residential Gateways as shown as figure 9. In [13], any possible connections in between MHP and OSGi are explored, in the context of Residential Gateways. With the respect of the work in [13], OWL-OS has been defined which means that adapt the OWL-based[14] Web Service ontology to the peculiarities of the OSGi services. Figure 10 has showed that the concept of OWL-OS ontology. According to this concept, it makes the services more easier based on operations-at-home and also allow a bundle to express the other services requirements. From [13] proposed that this automation would open the platform to ambitious applications of controlling the services at home, like automatically composes a service which triggers the ringing alarm, unlocks the doors, calls the fire station, etc.

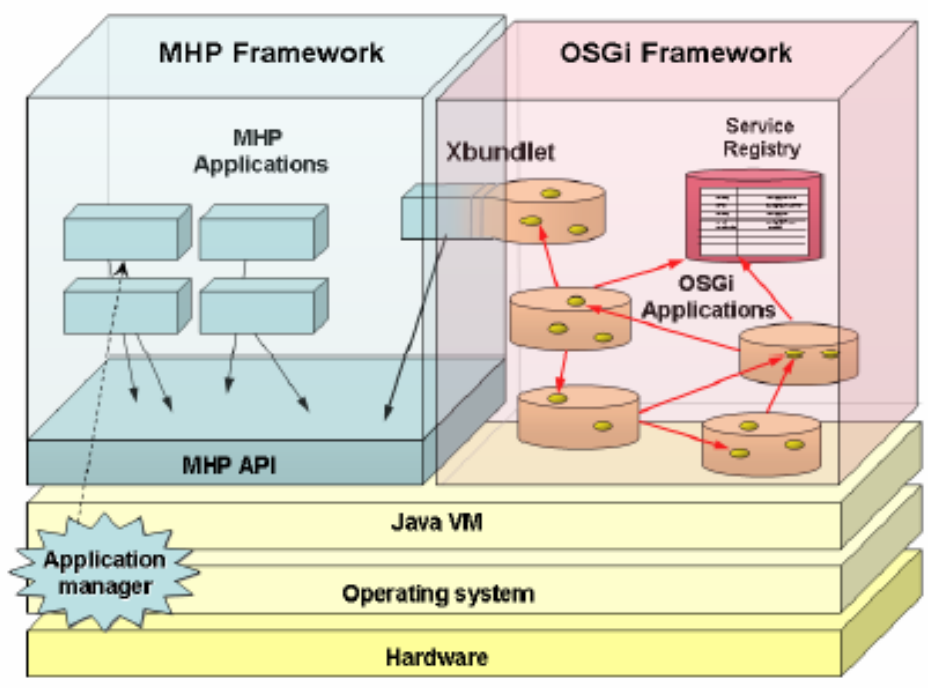

Figure 9 The XbundLET entity in between MHP framework and OSGi framework [13] 


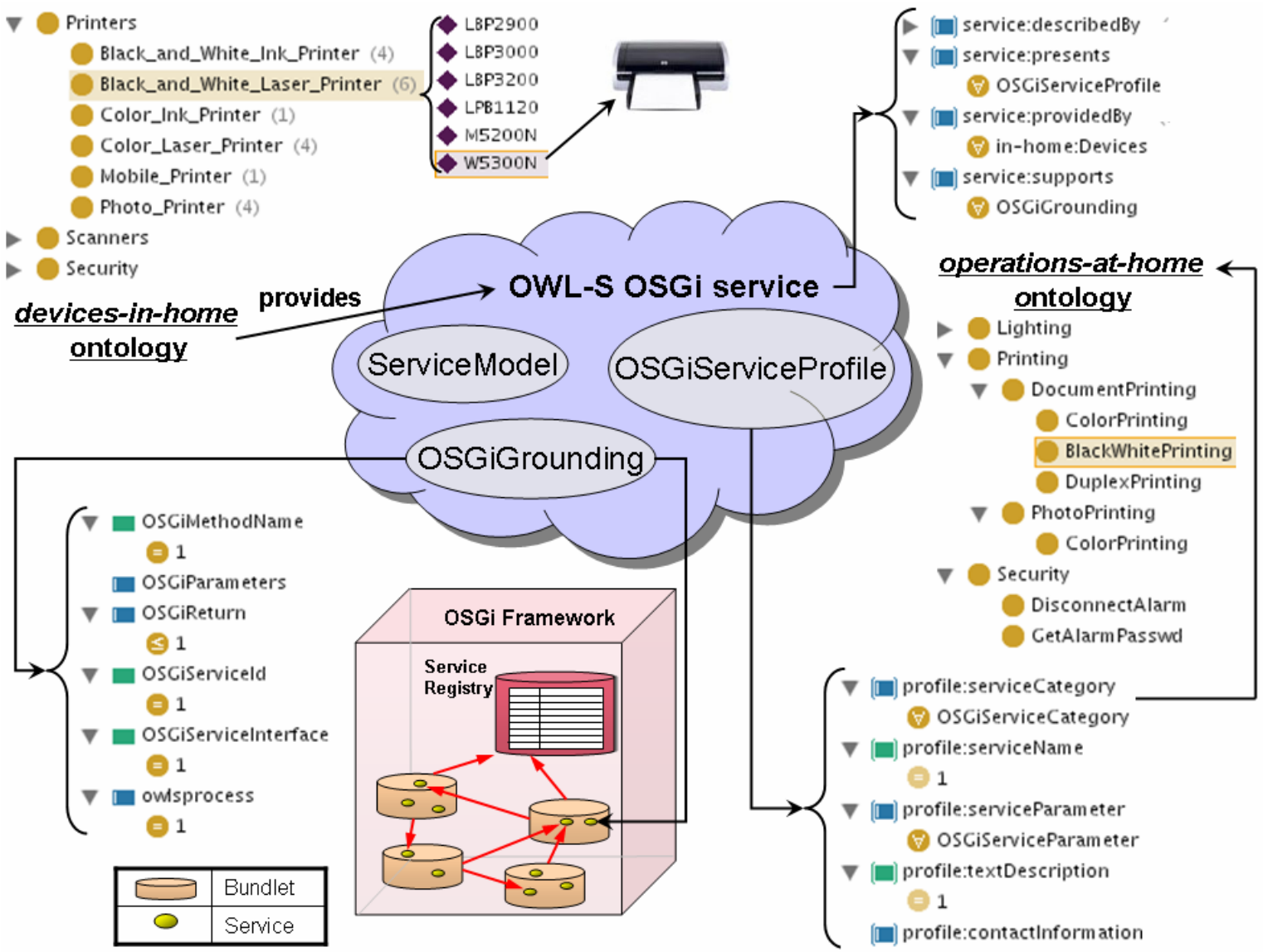

Figure 10 The OWL-OS ontology (OWL-OSGi Services ontology) [13]

Previous research has reported that designing smart health care technology is getting on demand. In [15], development of smart home architecture is focused on delivering intelligent health care. The coevolution algorithm used with the version of Enforced Sub Populations algorithm (ESP) in three types of experiments which are ESP with a central controller, ESP with distributed controller, and specially devoted to analyze the intelligent hardware sensors. In [15], it can concludes that analyzing data using collective intelligence technology will be vital from distributed sensors and also achieve the adaption of software modules in conventional computers and implementation of hardware into the system. The main feature of [15] is to develop a task without the particular each agent and reduce computing complexity associated to each intelligent hardware units (IHU). Figure 11 has showed that the working methodology for certain IHU. Not only that, a robustness system has been demonstrated to be processing with the intelligent hardware sensors and scalability of this architecture to achieve more efficient control of the system.

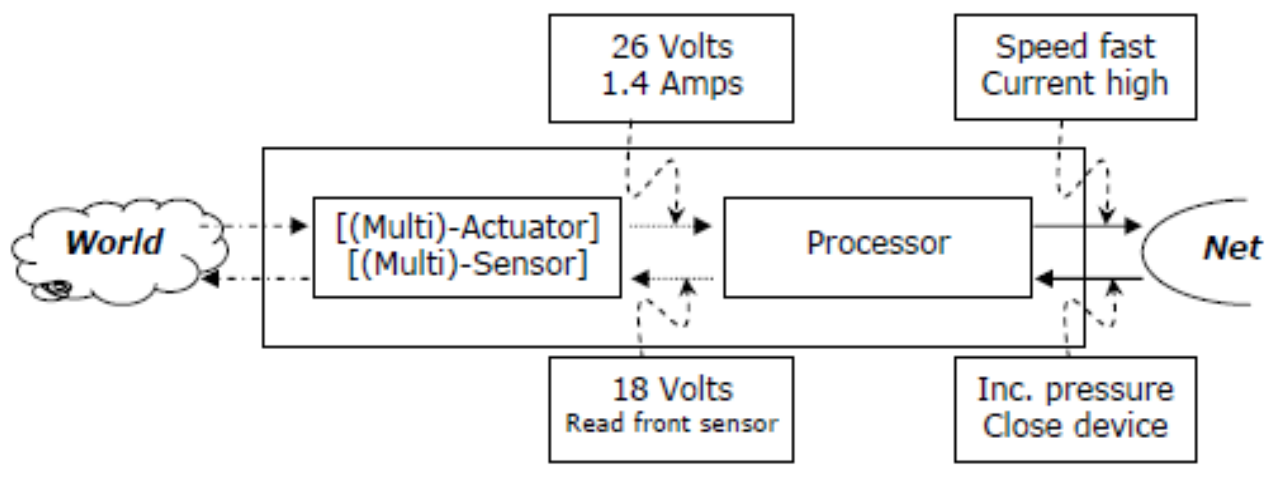

Figure 11 Working methodology for a certain intelligent hardware unit (IHU). [15] 
In [16] and in related references it was observed that the work of smart home is more emphasize in the latest technology to turn ordinary home into extraordinary. Programmable Logic Controller (PLC) as primary control unit, Global System for Mobile Communications (GSM), Short Messaging System (SMS) and others will be used in [16] to utilize advance and complex technologies, life is made easier and comfort for everyone under its roof. The aim of [16] is to develop a system by using GSM communication to notify user the current status of electrical appliances, ensure safety issues from any cases of accident that will caused by electrical appliances, and make improvement of the existing system in market. Figure 12 has showed that the flowchart of running Smart Home Automation by using GSM. In conclusion, [16] shows enable user to control the home appliances and prevent problems that happened in home automation system. In [16] will become commercial due to the advance technology is applied even the cost is high in the development.

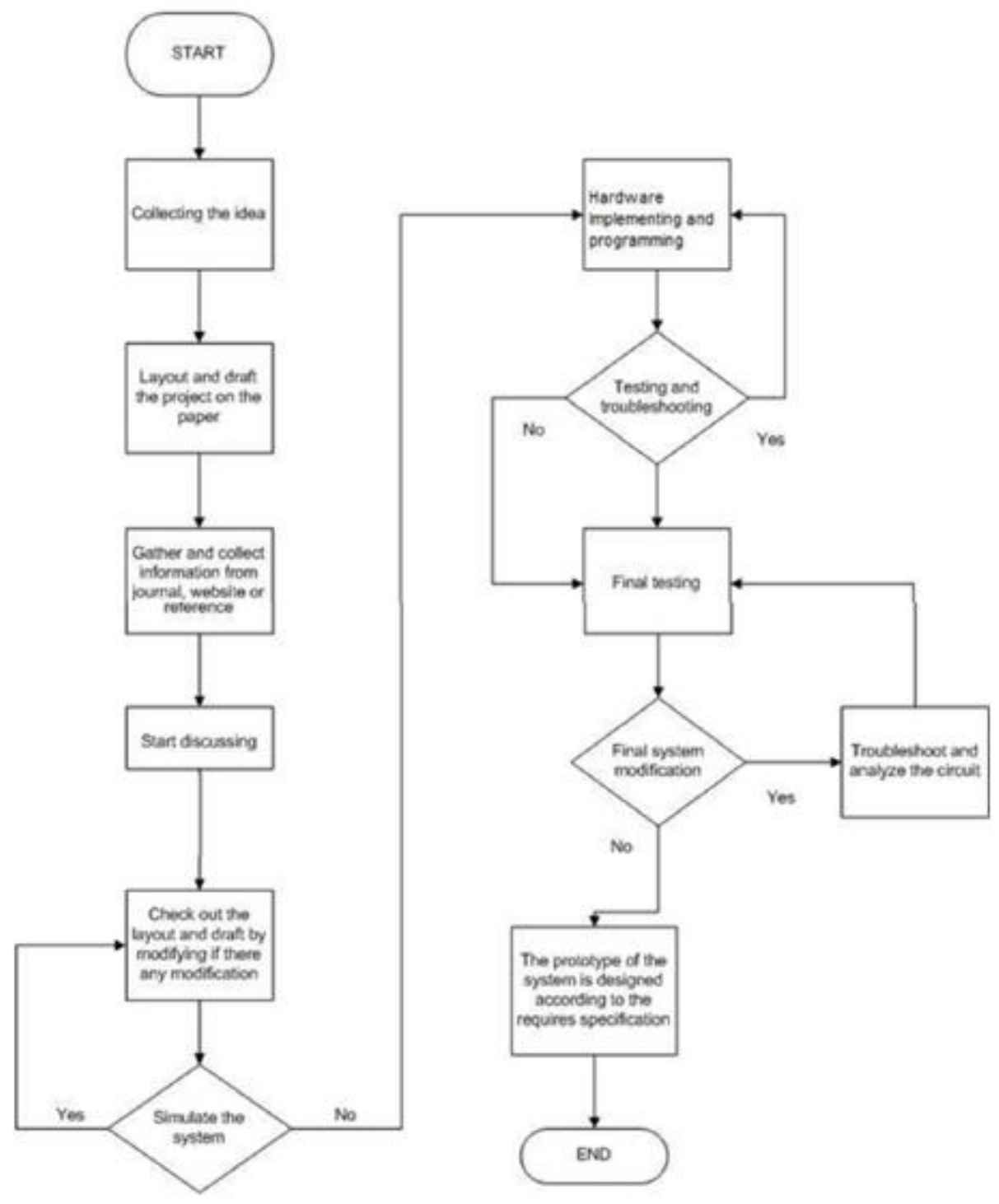

Figure 12 Flowchart of Smart Home Automation by Using GSM [16]

\section{V.SMART ENERGY MANAGEMENT METHODS}

From another research, [17] developed a framework called SMARTENERGY.KOM based on wireless sensor networks and human activity detection to realize energy efficient smart home. In this idea includes a set of electrical appliances to detect current related activity and monitor its fine-grained appliances-level energy consumption to avoid any wasting energy. In [17], the framework of 
EnergyAdvisor is applied to utilize the detection of activity based on its energy consumption, and recognized any appliances are wasting energy and informing the user about optimization potential. This SMARTENERGY.KOM framework include three main components as shown in Figure 13 which are data collection units with the aid of sensor using, data processing units with the aid of microcontroller and control server and data visualization and feedback unit with the aid of smartphone. The EnergyAdvisor framework is responsible to report all the activity detection and generate the energy saving recommendations to the user in the form of text messages. Based on the results, it can be concluded that the research introduced SMARTENERGY.KOM framework for conserving energy and also EnergyAdvisor framework has shown a significant potential for energy saving which was greater than 50\% for certain activities in smart homes as showed as table 5. In future work, [17] will focus on utilize the system consider of multiple and overlapping activities since the system do not detect any in that moment.

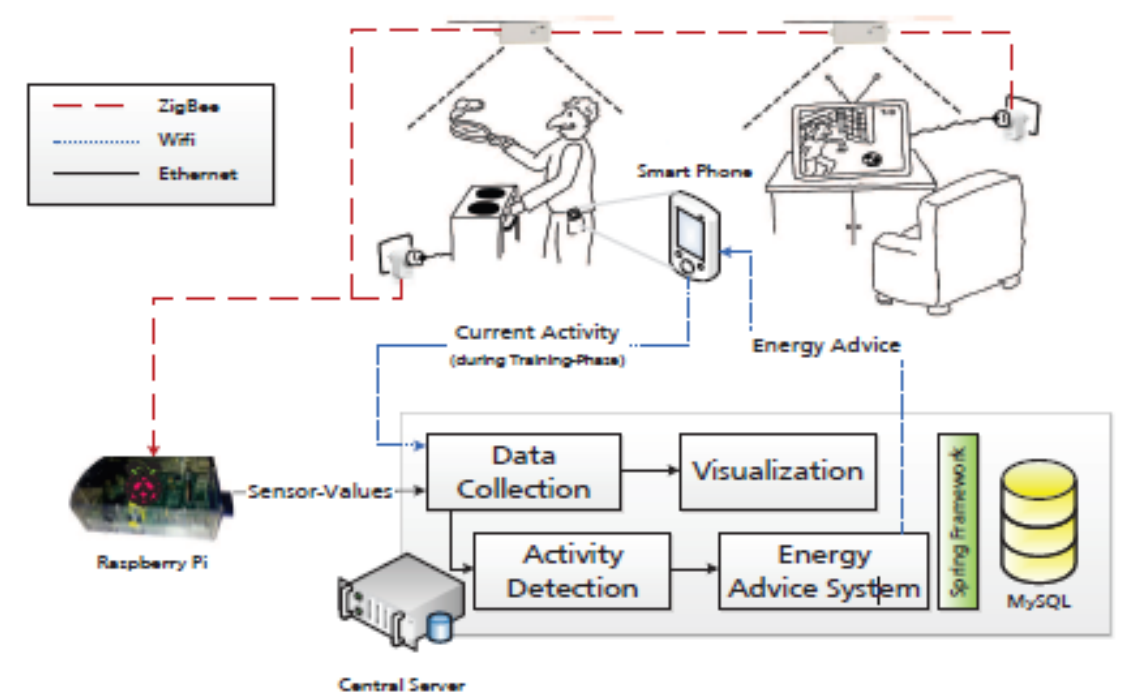

Figure 13 System architecture and network topology [17]

Table 5 Record of Saved Energy at Home [17]

\begin{tabular}{lccc}
\hline Activity & Consumed Energy & Potential Savings & Proportion \\
\hline Eating & $1818 \mathrm{Wh}$ & $1231 \mathrm{Wh}$ & $67.70 \%$ \\
\hline Ironing & $287 \mathrm{Wh}$ & $4 \mathrm{Wh}$ & $1.54 \%$ \\
\hline Listening to Radio & $218 \mathrm{Wh}$ & $71 \mathrm{Wh}$ & $32.72 \%$ \\
\hline Making Tea & $1118 \mathrm{Wh}$ & $84 \mathrm{Wh}$ & $7.47 \%$ \\
\hline Not at Home & $1258 \mathrm{Wh}$ & $647 \mathrm{Wh}$ & $51.47 \%$ \\
\hline Reading & $244 \mathrm{Wh}$ & $114 \mathrm{Wh}$ & $46.89 \%$ \\
\hline Sleeping & $3644 \mathrm{Wh}$ & $1952 \mathrm{Wh}$ & $53.56 \%$ \\
\hline Cutting Bread & $20 \mathrm{Wh}$ & $13 \mathrm{Wh}$ & $65.30 \%$ \\
\hline Watching TV & $18682 \mathrm{Wh}$ & $176 \mathrm{Wh}$ & $0.94 \%$ \\
\hline
\end{tabular}

In another research from [18] presented that Wireless Home Automation system (WHAS) using IoT to make automatic control and monitoring of household appliances and residential house features in order to save the electric power and human energy. Figure 14 has showed a detailed design for the proposed system. In [18] involves three main components which are local hardware and local network devices to connect household appliances, web server to connect the system with the local hardware and mobile smart devices and also deal with the records stored in the database of the system, mobile smart device to run Android operating system to make customers contact with and manage the in home devices via the server and also provide a non-complex graphical interface for controlling easily the automated machines at home. With [18] it involves different intelligent subsystems which are lighting system, electrical appliances control system, window curtain system, environment control system and safety 
assurance system. Software proposed is responsible to control all the subsystem. At last it will send the commands to the server and then it sends the commands to the microcontroller to enable or disable the connected relay which place in plug points. Figure 15 has showed that a data flow diagram in the system. In [18] has clearly shown that IoT able to work satisfy by connecting simple appliances and controlled remotely through internet. This designed system able to monitor the sensor data, actuates a process according to requirement, and stores sensor parameters in the cloud (Gmail). This makes user easier and convenience to use all the time.

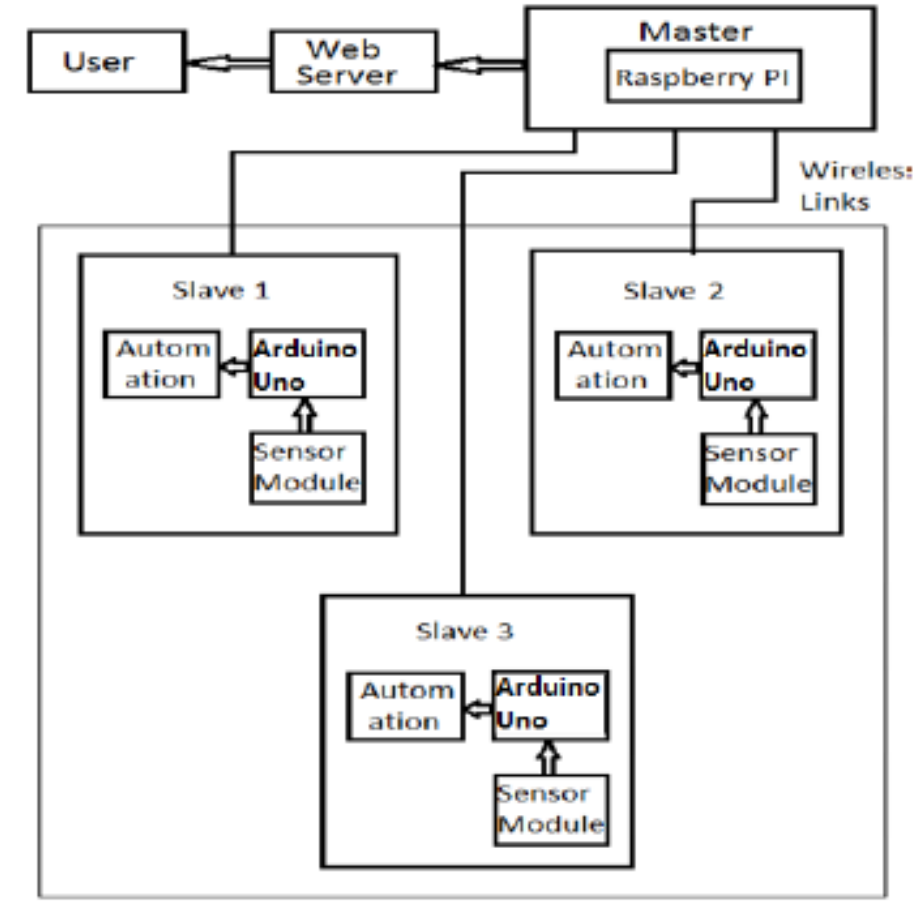

Figure 14 The Detailed Design [18]

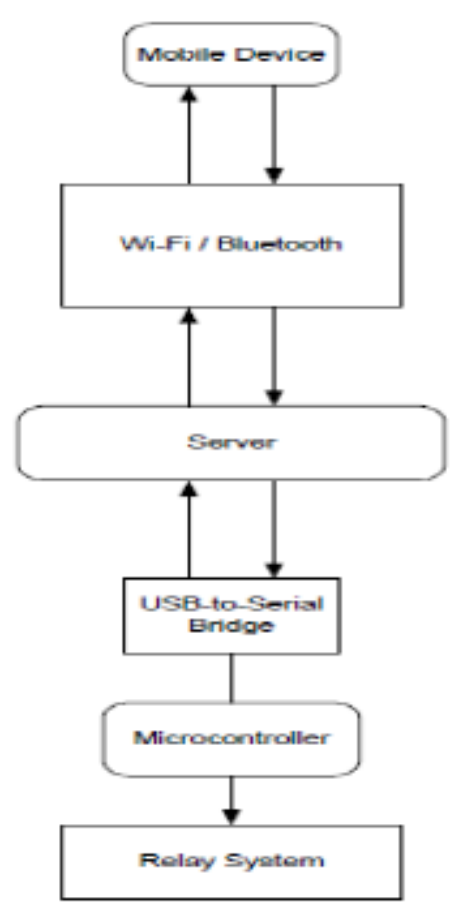

Figure 15 The Data Flow Diagram [18] 
This view is supported by [19] which writes that the smart technologies nowadays design in smart homes is fulfill consumers' behavior and targeted to reduce energy consumption. In [19] is focused on the perception of Singapore households on smart technology and aim to reduce energy consumption regarding on the areas of current research include energy consumption in Singapore households, public programs and policies in energy savings, use of technology in energy saving, and household perception of energy savings in smart homes. It has been made a research of three case studies that have implemented smart homes to save energy, together, these studies outlines that the residents are seem lack of general awareness about proper energy saving behavior and proper guidance, less of understanding well to the appliance energy consumption such as smart meter. Nevertheless, a portion of residents showed their households' behavior towards saving energy positively changed due to installation of smart home technologies. In figure 16 has showed that the motivation to adopt technology at home based on the opinions of participants in the current survey. In summary, households in Singapore have shown concerns on environmental issues and willing to invest in smart home technologies to address them once they get the information and importance of saving energy. Not only that, to apply smart home technologies in Singapore must integrate into public services and utility sectors but not only saving energy and also provide a service which giving notifications to turn on certain appliances through mobile gadgets or house consoles.

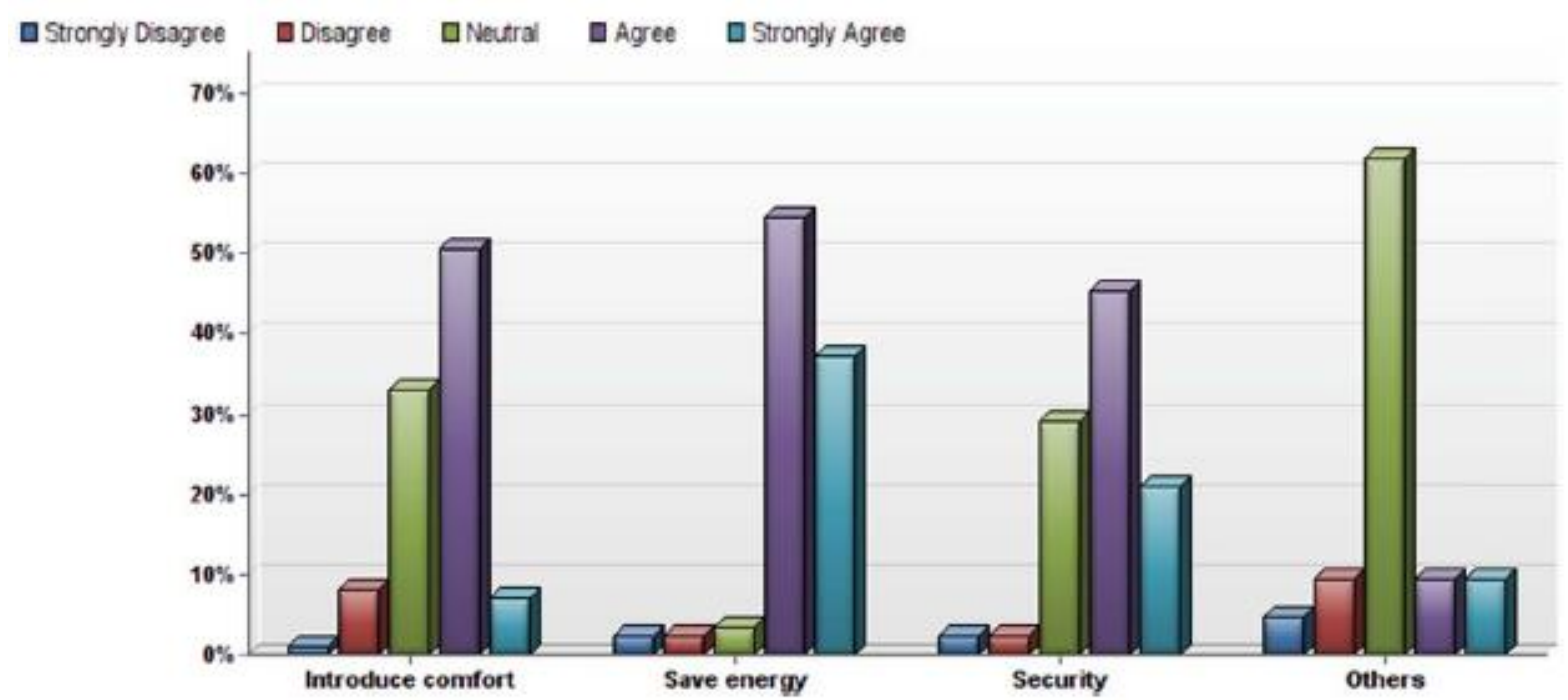

Figure 16 Motivations to adopt technology at home [19]

Similarly, in [20] analyze that a smart home technology would provide energy management technique for energy saving but not only care about security and comfort for people. In [20] proposed that the effectiveness way based on a static correlation between the power consumption and saving. In [20], it concludes a set of sensors such as temperature sensor and occupancy sensor and certain specific software to manage intelligently to control the devices of home appliances to reduce the energy consumption. From the data analyze in calculation by the specific software, it can concludes that the increase in power saving is accompanied by a great increase in cost saving from the assumption calculations and it showed as figure 17. This shows that a home energy management able to maximize the action of energy saving and hit the economical target but not individual need only. 


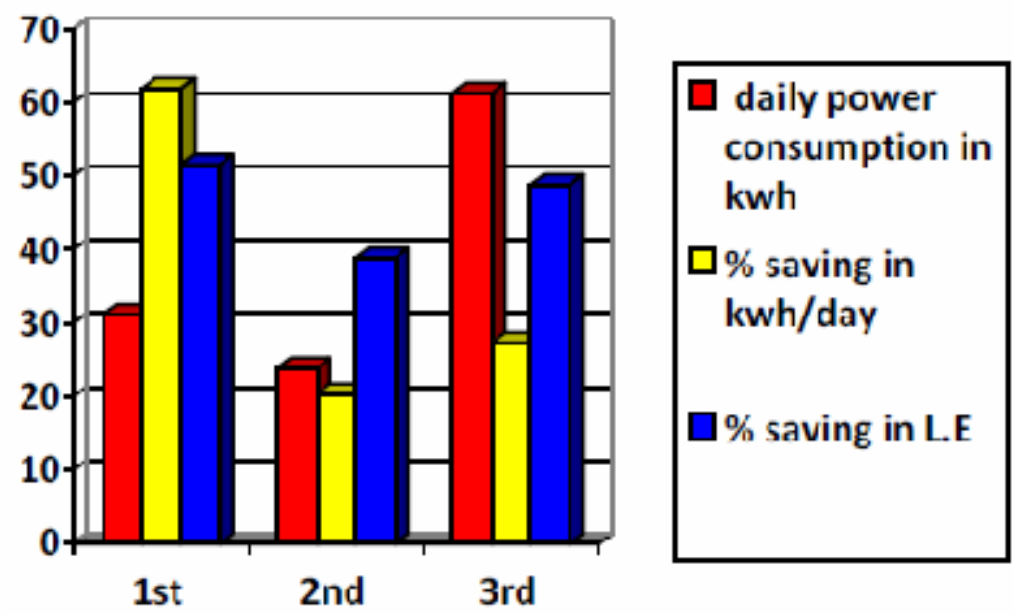

Figure 17 The daily consumption, percentage saving in power and in electric bill for the previous trials. [20]

\section{CONCLUSIONS}

In this paper, the review related to energy smart management system was presented. This research provides information on related works about using smart technologies in managent of indoor saving energy. The review focused on methods of smart systems with different technologies.

\section{ACKNOWLEDGMENT}

The authors would like to thank the faculty of engineering technology, University Malaysia Pahang, for providing continuous facility. The present research was made possible availing facility provided by MRS grant.

\section{REFERENCES}

1. World Energy Statistics 2016. 2016, France: INTERNATIONAL ENERGY AGENCY. 789.

2. H.F.Castleton, V.S., S.B.M. Beck, J.B. Davison, Green roofs; building energy savings and the potential for retrofit. Energy and Buildings, 2010. 42(10): p. 10.

3. Niachou, A., et al., Analysis of the green roof thermal properties and investigation of its energy performance. Energy and Buildings, 2001. 33(7): p. 719-729.

4. Oyeshola F. Kofoworola, S.H.G., Life cycle energy assessment of a typical office building in Thailand. Energy and Buildings, 2009. 41(10): p. 8.

5. N. Yamtraipat, J.K., J. Hirunlabh,J. Kunchornrat, Assessment of Thailand indoor set-point impact on energy consumption and environment. Energy Policy, 2006. 34(7): p. 6.

6. Rune Vinther Andersen, B.O.a.J.T., Simulation of the Effects of Occupant Behaviour on Indoor Climate and Energy Consumption, in REHVA World Congress, J. Finland Editor. 2007, FINVAC: Helsinki, Finland.

7. Danish Building code. 1998; Available from: http://www.ebst.dk.

8. Su-hong Shin, K.-h.D., Byoung-soo Koh, A Study of Smart Power Control Algorithm Using RF Communication in Smart Home Environment. International Journal of Distributed Sensor Networks, 2013. 2013(690902): p. 8.

9. Lim, T.W., RF switch controller power supply apparatus of lamp. 2016, Google Patents.

10. Joaquin Lopez Fernandez, D.P.L., Enrique Paz Domonte, An Integrated and Low Cost Home Automation System with Flexible Task Schedulling, in XV Workshop of Physical Agents. 2014, ResearchGate: Leon, Spain.

11.Fernandez, J.L., et al. Using hierarchical binary Petri nets to build robust mobile robot applications: RoboGraph. in 2008 IEEE International Conference on Robotics and Automation. 2008. 
12. Shruthi Suresh, S.P.V., A Review on Smart Home Technology in 2015 Online International Conference on Green Engineering and Technologies (IC-GET 2015). 2015, IEEEXplore: Coimbatore, India.

13. Manuel Ramos Cabrer, R.P.D.R., Ana Fernandez Vilas, Jose J. Pazos Arias, Jorge Garcia Duque, Controlling the Smart Home from TV. IEEE Transactions on Consumer Electronics, 2006. 52(2): p. 9.

14. OWL-S: Semantic markup for Web Services. 1.1 Release 2004, The OWL Services Coalition.

15. Bahón, C.A., R.A.T. Lara, and A.i.I.I. Universitat Politècnica de Catalunya. Departament d'Enginyeria de Sistemes, Distributed Intelligence for Smart Home Appliances: ESAII-RR-04-01. 2004.

16. S.H. Husin, A.A.N., N. M. Z. Hashim, Y. Yusop, A.S Ja'afar, Home Electrical Appliances Smart System. International Journal of Computer Science and Mobile Computing, 2013. 2(9): p. 7.

17. Alaa Alhamoud, F.R., Andreas Reinhardt, Frank Englert, Daniel Burgstahler, Doreen Bohnstedt, Christian Gottron, Ralf Steinmetz, SMARTENERGY.KOM: An Intelligent System for Energy Saving in Smart Home, in 39th Annual IEEE Conference on Local Computer Networks Workshops. 2014, IEEE: Edmonton, AB, Canada. p. 685-692.

18. Rutuja D. Ekatpure, D.I., Android based Interactive Home Automation System through Internet of Things. International Journal of Advanced Research in Electronics and Communication Engineering (IJARECE), 2016. 5(4): p. 5.

19. Abhishek Bhati, M.H., Ching Man Chan, Energy conservation through smart homes in a smart city: A lesson for Singapore households. Energy Policy, 2017. 104: p. 110.

20. Ashour, E.I.I.A.P.D.H., Energy Saving Through Smart Home. The Online Journal on Power and Energy Engineering (OJPEE), 2011. 2(3): p. 5. 